\title{
Attentional distribution in the visual field during same-different judgments as assessed by response competition
}

\author{
KAIYU PAN and CHARLES W. ERIKSEN \\ University of Illinois, Urbana-Champaign, Illinois
}

\begin{abstract}
Judgments of same and different on a comparison task have been found to be subject to response competition if an irrelevant stimulus is presented in the display along with the target stimuli. For example, the reaction time for judging two letters the same is markedly increased if a different but irrelevant letter is also present in the display (C. W. Eriksen, O'Hara, \& B. [A.] Eriksen, 1982). We have made use of this competition effect to map the visual attentional field in two dimensions. In two experiments, we varied the size of the attended area by varying the separation of the comparison stimuli. The boundaries of the attended area were mapped by varying the location of a response-competitive irrelevant noise letter. On this task, the attended area was found to be elliptical in shape, with the location of the target stimuli defining the major axis. The minor axis of the ellipse increased in direct proportion to increases in the major axis. Rather than interpret these field effects in terms of areas of enhanced processing, we propose that instead they represent the limits or failures in inhibition of competing stimulation.
\end{abstract}

One of the most important characteristics of a concept of attention is the process or means by which one stimulus is selected for processing from among a number of equally potent alternatives. For the case of visual attention, there is controversy over whether this selection is based on objects or on spatial location. Object-based theories (e.g., those of Driver \& Baylis, 1989; Kahneman \& Henik, 1981; Prinzmetal, 1981; van der Heijden, 1992) emphasize that selection is based on objects that preattentive processes have constructed in the visual field, whereas space theories posit that attention or attentional resources are directed or distributed to locations in the visual field.

Location as opposed to other dimensions such as color, size, and orientation is given a special status in space theories of attentional selection (see, e.g., Tsal \& Lavie, 1988). Although there are different versions of space theories, the spotlight models (see, e.g., LaBerge, 1983; Posner, Snyder, \& Davidson, 1980; Tsal, 1983), the zoom lens model (C. W. Eriksen \& Yeh, 1985), and the gradient models (see, e.g., Downing, 1988; LaBerge \& Brown, 1989) all conclude that the attentional focus has a measurable extent in the visual field that limits or selects the information available for detailed processing.

The evidence for the spatial nature of visual attentional selection comes from two main sources. The first con-

This research was supported by Public Health Service Research Career Program Award K06-MH22014 to C.W.E. and by United States Public Health Service Research Grant MH01206, also to C.W.E. Correspondence concerning this article should be addressed to $\mathrm{C}$. W. Eriksen, Department of Psychology, University of Illinois, Urbana-Champaign, 603 East Daniel Street, Champaign, IL 61820. sists of results obtained with the use of single-item displays in which the location of the item varies from trial to trial. If the item location is precued by $50-150 \mathrm{msec}$ before target onset, the reaction time (RT) for identification is reduced by as much as $30-40 \mathrm{msec}$ (C. W. Eriksen \& Hoffman, 1973, 1974). This finding has been confirmed by a number of other investigators (e.g., Tsal, 1983; van der Heijden, Wolters, \& Enkeling, 1988), and van der Heijden, Schreuder, and Wolters (1985) have shown that recognition accuracy is also improved when target location is precued.

These results have been interpreted in terms of the head start with which the precue provides the attentional spotlight or focus in aligning with the target location in the visual field. However, alternative interpretations have been proposed. Duncan (1980) has argued that location cues operate as criteria for selection in the same way as do color, size, orientation, or other dimensional cues. In the absence of a location precue, attention has to address each possible location in the visual field until the target is found. In his view, the precue expedites processing by eliminating this search of the "empty" area in the visual display. (See Tsal, 1983, for a critique of this position.)

Murphy and C. W. Eriksen (1987) also have suggested a nonattentional interpretation of the precuing effect for single-target displays. They note the considerable evidence that the visual system processes location and features with at least partial independence (see, e.g., Coles, Gratton, Bashore, C. W. Eriksen, \& Donchin, 1985; Estes, 1978; Treisman \& Gelade, 1980). Further, Treisman and colleagues (Treisman \& Gelade, 1980; Treisman \& Souther, 1985) have proposed that the features of a form stimulus are separately processed and are integrated into a shape 
or identity by their common location on a location map that has been independently processed. Since we can reasonably assume that both feature and location processing have variable latencies, to give location processing a head start by means of a location precue would, on the average, result in less time for the integration of features on the location map. The time saved would be even greater if, as suggested by the results of Coles et al. (1985), location processing tended to be slower than feature analysis. If precues worked in this manner, it would account for the decrease in choice RT obtained with single-item displays and, more importantly, would essentially render these precuing experiments moot as far as an attentional interpretation was concerned.

The second source of evidence for a spatial distribution of an attentional focus is more impressive. It consists of experiments performed to study the extent to which nontarget stimuli are processed along with the target stimulus. In a number of these experiments (e.g., those of LaBerge \& Brown, 1986; Miller, 1991; Yantis \& Johnston, 1990), researchers have employed the responsecompetition paradigm introduced by $\mathrm{C}$. W. Eriksen and Hoffman (1973) and B. A. Eriksen and C. W. Eriksen (1974). In the basic paradigm, choice RT is employed, and the target forms are divided into two classes, each of which requires a separate identifying response. When a visual display is presented, the target on that trial occurs in a clearly defined location. The response-competition effect consists in an elevated RT when the display also contains in an irrelevant location a form from the other response class (noise form). If, on the other hand, the noise form is from the same response class as is the target on that trial, little or no effect on RT is obtained. In the latter case, even though the noise letter is processed along with the target, the response associated with the noise form is compatible with the target response and there is no response competition (Coles et al., 1985; C. W. Eriksen, Coles, Morris, \& O'Hara, 1985).

The response-competition effect provides a sensitive measure of the location or distribution of the attentional focus in the visual field. The distance of the incompatible noise form from the designated target location can be systematically varied and the size of the response-competition effect assessed (C. W. Eriksen \& Hoffman, 1973; C. W. Eriksen \& St. James, 1986; Miller, 1991; Murphy \& C. W. Eriksen, 1987). The presence of response competition indicates that the incompatible noise letter has been processed along with the target, whereas the absence of competition indicates that the attentional focus has been narrow enough or the selection precise enough so as to exclude the irrelevant stimulus.

The results from these experiments have shown that the response-competition effect decreases with increasing target-noise separation (C. W. Eriksen \& Hoffman, 1973; C. W. Eriksen \& St. James, 1986; Miller, 1991; Murphy \& C. W. Eriksen, 1987; Yantis \& Johnston, 1990). If sufficient time in the form of a location precue is provided, incompatible noise stimuli located beyond about a degree of visual angle from the target are found to have no measurable effect (C. W. Eriksen and Hoffman, 1973; Murphy \& C. W. Eriksen, 1987). This strongly suggests that visual attentional selection can be precise enough to exclude irrelevant stimuli if there is a minimal spatial separation between the attended stimulus and competing stimuli (Miller, 1991; Yantis \& Johnston, 1990).

Similar spatial effects have been obtained with manipulations of the spatial extent of the attentional focus (see, e.g., Downing \& Pinker, 1985; C. W. Eriksen \& St. James, 1986; LaBerge, 1983; LaBerge \& Brown, 1986, 1989). C. W. Eriksen and St. James (1986) manipulated the spatial extent of the attentional focus by varying the number of contiguous positions on a circular display that were precued. Incompatible noise stimuli located within the cued area produced significantly greater response competition than did noise letters outside the precued area. Furthermore, the amount of response competition produced by incompatible noise letters outside the cued area decreased as the distance of these noise letters from the cued area increased.

LaBerge and Brown (1986) manipulated the size of the attentional focus by varying the difficulty of the required discrimination. They assumed that the more difficult the discrimination, the more finely drawn would be the focus. The response competition produced by an incompatible noise letter located at a constant distance from the target decreased as the focus became more precise.

The research summarized above shows quite clearly that attention has a measurable extent in the visual field, but there remain questions about the shape or configuration of the focus as well as about how this attended area is produced. LaBerge and Brown (1989) conceive of the attended area as a gradient that can be contracted or extended according to task demands, but their research has explored only the single linear dimension of this gradient. Spotlight models have not directly addressed the shape issue, but this analogy implies that the attended area is circular in shape. It may be, however, that the attended area is configured to suit the task. In this case, we might ask whether the attended area is homogeneous and circumscribed or whether it permits regions of varying concentration, as seems to be allowed for in the gradient model of LaBerge and Brown (1989).

In both the gradient and the spotlight conceptions of the attentional field, it is assumed that the attended area is one of enhanced processing and that interference from distractors is due to their enhanced processing along with that of the target stimulus. However, Hughs and Zimba $(1985,1987)$ have proposed that the area around attended targets represents inhibition. From this conception, the interference from distractors would represent failures or limits on the inhibition process, and the area within which distractors are effective would map out the borders of the inhibitory field. This border would be the extent to which inhibition extends toward the attended object rather than the demarcation line of enhanced processing extending out from the attended object. After presenting the results 
of our experiments, we will more fully consider an interpretation of the attentional field as an inhibition-free area.

In the present research, we have used a same-different task to study the attentional distribution in the visual field. This task has the advantage of requiring attention to both members of the target pair and allows us to manipulate in two dimensions the size of the area that needs to be attended. It also permits us to determine whether there is a single circumscribed area that is attended or whether attention can be simultaneously concentrated on two separated locations in the visual field. The two forms constituting the target pair can be separated by varying distances in both the vertical and horizontal dimensions, and since same-different judgments have been shown to be quite sensitive to response-competition effects (C. W. Eriksen \& O'Hara, 1982; C. W. Eriksen, O'Hara, \& B. [A.] Eriksen, 1982; Keren, O'Hara, \& Skelton, 1977; Krueger, 1978; O'Hara, 1980; St. James \& C. W. Eriksen, 1991), the extent or two-dimensional shape of the attended area can be assessed by probing the visual field at different locations with response-incompatible noise stimuli.

Keren et al. (1977) were among the first to show that the RTs on same trials in a letter-matching task were appreciably increased if a nonmatching noise letter was presented in the display in an irrelevant location. C. W. Eriksen et al. (1982) have presented a response-competition interpretation of the effect and extended the research to show that RTs on different trials are increased if a nonrelevant noise letter that matches one of the target letters is present in the display (see also Garner, 1988). Most recently, St. James and C. W. Eriksen (1991) have tied the effect directly to the activation of competing responses. It is consistent with the results from two-choice RT tasks that the presence of response-compatible noise letters (i.e., a letter identical to the targets on same trials and a letter different from both targets on different trials) has little or no effect on judgment RT.

\section{EXPERIMENT 1}

The experimental task measured RT for same and different judgments of target letter pairs. In addition to the target letters, each display contained a noise letter in an irrelevant position. On same trials, this noise letter could be either response compatible (identical to the target letters) or incompatible (different from the target letters). On different trials, the noise letter was always response incompatible, since it was identical to one of the target letters. However, in this experiment, the performance on same trials was our primary diagnostic since the effect of incompatible noise on same judgments is more robust and sensitive (Farell, 1985; Keren et al., 1977).

To produce different sizes of the attentional field, three different target separations were manipulated. Correspondingly, three distances of the noise letter from the targets and the fixation point were manipulated independently from and orthogonally to the target separations.
This design permits the determination of the effective attentional field and of whether processing is uniformly distributed within this field. For example, if the attentional field is circular in shape like a spotlight, the diameter of this circle would roughly correspond to the distance between the letters constituting the target pair. An incompatible noise letter anywhere within this circle should elevate RT by approximately the same amount if processing within the field is uniform. On the other hand, incompatible noise letters falling outside the circle should have little or no effect on RT. The location of compatible noise letters at all target distances should have minimal effects on RT, given the results of the prior research that has been summarized above.

\section{Method}

Subjects. Five women and 7 men, undergraduates at the University of Illinois, Urbana-Champaign, served as paid volunteers. All were right-handed and had normal or corrected-to-normal vision.

Apparatus and Stimuli. The stimuli were presented on a Zenith CRT connected with and controlled by a Zenith Data Systems computer. Luminance was maintained at $37 \mathrm{fL}$, as measured by a Spectra brightness spot meter. The subjects viewed the stimuli binocularly through a face mask to keep the stimulus distance constant. They initiated the onset of the stimulus by pressing a button held freely in the left hand. This triggered the computer to present a display. A handrest located to the right of the subject contained a small lever that could be moved either to the left or to the right, depending on the category judgment made by the subject. When the subject moved the lever in either direction, the computer recorded which response the subject had made and the RT in milliseconds.

The target and noise letters were all white uppercase $\mathrm{Hs}$ and Ss. Each letter subtended $0.23^{\circ}$ of visual angle in height. The fixation point was a cross, ",$+ "$ measuring $0.1^{\circ}$, located at the center of the display.

There were four different target displays, consisting of all four possible permutations of the letters $\mathrm{H}$ and $\mathrm{S}$. These targets provided two same displays and two different displays. There were three kinds of same displays corresponding to the different noise conditions. In the no-noise condition (control), the display consisted only of the two target letters to be matched. Under the noise-compatible condition, either the noise letter $\mathbf{H}$ appeared with the target pair of Hs or the noise letter S appeared with the target pair of Ss. For the noise-incompatible condition, either the noise letter $S$ was presented with the target pair of $\mathrm{Hs}$ or the noise letter $\mathrm{H}$ was presented with the target pair of Ss.

For the different displays, there was a no-noise control condition in which the target pair $\mathbf{S}$ and $\mathrm{H}$ appeared as the sole letters in the display. On the remainder of the different trials, $\mathrm{S}$ or $\mathrm{H}$ appeared as incompatible noise with the target pair.

The target letters were arranged either vertically or horizontally. For half the subjects, the target letters were always positioned one above and one below the fixation point, their positions corresponding to the clock positions $12: 00$ and 6:00. The two target letters were separated by $0.5^{\circ}, 1.0^{\circ}$, or $2.0^{\circ}$ of visual angle $\left(0.25^{\circ}, 0.5^{\circ}\right.$, or $1.0^{\circ}$ from fixation). For the other 6 subjects, the target letters were always positioned one to the left and the other to the right of the fixation point, their positions corresponding to the 3:00 and 9:00 positions. They were also separated by $0.5^{\circ}, 1.0^{\circ}$, or $2.0^{\circ}$ of visual angle. There were three distances for the noise letter from the fixation point, namely, $0.25^{\circ}, 0.5^{\circ}$, or $1.0^{\circ}$ of visual angle. Figure 1 shows the vertically arranged displays and the relative locations of the targets and noise letters.

For the subjects with the vertically arranged targets, the noise letter was placed to the right or left of the fixation point. The noise 
Target Distance Separation

0.5 (deg) $\quad 1.0$ (deg) $\quad 2.0$ (deg

$\mathbf{S}$

$\begin{array}{rrrr}\substack{0.25 \\ \text { (deg) }} & \mathbf{S} & \mathbf{S} & \\ & \mathbf{S} & \mathbf{S}+ & \mathbf{S}+\end{array}$

$\frac{s}{s}$

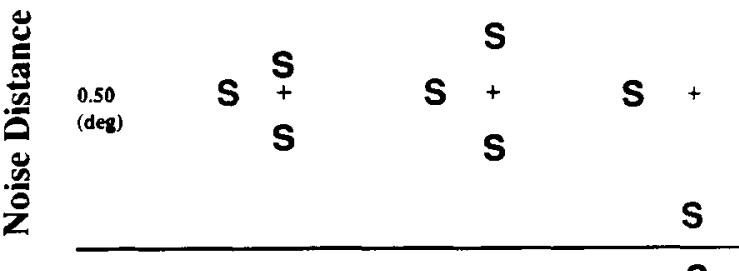

$\mathbf{S}$

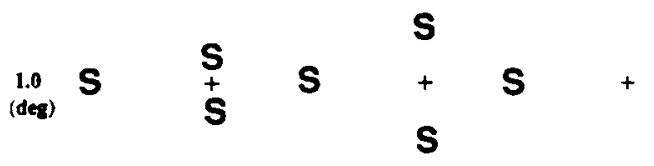

S

Figure 1. Some of the vertical displays used in Experiment 1, showing the locations of the targets and noise stimuli. The relative distances between the target pairs and the noise letters are the same as those in the experimental displays. The displays shown are for compatible noise on same trials. Note that the position of the noise letter to the right of the fixation point also occurred equally often in a block of trials.

letter appeared to the right and left equally often. For the subjects with the horizontally arranged targets, the noise letter was similarly located above or below the fixation cross.

Procedure. The subjects were instructed to initiate each trial by pressing a button (held in the left hand) when the fixation point was in clear focus. The fixation point remained for $300 \mathrm{msec}$ before it was replaced by the stimulus field for $175 \mathrm{msec}$. The stimulus field was then followed by the blank field for $1,325 \mathrm{msec}$, and, upon termination, the fixation cross reappeared. The subjects were instructed to compare the two targets on the basis of physical identity and to move the response lever with the right hand to the left (or the right) if the stimuli were physically identical or to the right (or the left) if they were different; these response directions were counterbalanced across subjects. The subjects were also instructed to attend only to the target letters. They were told that the target letters always appeared in exactly the same locations with reference to the fixation point within every block and that any extra letter that appeared in the display was to be ignored. Their task was merely to respond "same" or "different" to the target letters only. The subjects were informed of the distance between the target letters at the beginning of each block. They were further instructed to respond as quickly as possible but to avoid guessing. The subjects were also given accuracy and speed information after each trial. If they failed to respond within $1.5 \mathrm{sec}$, an "error" feedback was given.

Each subject participated in three sessions. The first session was considered to be practice, and data collected during this session were excluded from analyses. Before data were collected during the other two sessions, 12 warm-up trials were given.

During each session, nine blocks of trials were presented. The three different target separations were presented in separate blocks, with three blocks for each target separation in each session. The control condition and three different noise distance conditions were randomly arranged within blocks. All blocks contained an equal number of same and different target displays, different noise letter distances, noise at the left or right (or top or bottom), and an equal number of $S$ and $H$ pairs. In total, there were 52 trials per block. The trials within each block were randomly presented. Error trials were rerun later in the block. The order of block presentation was also arranged within sessions to balance practice effects.

\section{Results}

Same judgments. The RT values for same judgments were analyzed in a between-within analysis of variance (ANOVA) with the between-subject effects for the groups that received the vertically oriented targets and the horizontally oriented targets. The three variables of target distance, noise distance, and noise compatibility were within-subject effects.

The effect for vertical versus horizontal displays was not significant $[F(1,10)=1.95, p>.05]$, but this variable interacted with target separation $[F(1,20)=26.9$, $p<.0001]$. At the closest target separation, vertical and horizontal displays did not differ in RT, but as separation increased, RTs were relatively faster with the horizontal displays. The interaction is most likely due to the greater acuity along the horizontal meridian of the eye as eccentricity increases relative to the vertical meridian. Display orientation did not interact with any of the other variables.

The main effect of target separation was expected $[F(2,20)=131.36, p<.0001]$ on the basis of declining acuity with increasing eccentricity. Research has shown that as acuity declines, RT increases (e.g., C. W. Eriksen \& Schultz, 1977; Haber \& Hershenson, 1974). Thus, RT increased as targets moved farther apart $\left(0.5^{\circ}\right.$, $\left.501 \mathrm{msec} ; 1.0^{\circ}, 532 \mathrm{msec} ; 2.0^{\circ}, 581 \mathrm{msec}\right)$. On the other hand, RT decreased $[F(12,20)=18.00, p<.0001]$ as the noise letter moved farther away from the fixation point $\left(0.25^{\circ}, 550 \mathrm{msec} ; 0.5^{\circ}, 536 \mathrm{msec} ; 1.0^{\circ}, 528 \mathrm{msec}\right.$; and for the no-noise control, $533 \mathrm{msec}$ ). In agreement with the expectations and prior findings summarized above, an incompatible noise letter produced significantly higher RTs $[F(1,10)=18.86, p<.005]$ than did a compatible noise letter.

Our major interest is in the interaction between noise distance and compatibility $[F(2,20)=7.18, p<.005]$ and in the three-way interaction of these two variables with target separation $[F(4,40)=3.12, p<.05]$. The nature of these interactions can be seen in Figure 2, where mean RT is shown for compatible and incompatible noise for each of the three target separations as a function of the noise distance from fixation. The figure also shows the mean RT obtained in the no-noise control condition at each of the target separations.

Separate analyses of variance for the noise-compatible and noise-incompatible conditions showed that these two conditions had quite different results for noise distance (the control condition was included in the analysis). In the noise-compatible condition, the only significant effect was target separation $[F(2,22)=31.44, p<.0001]$, 

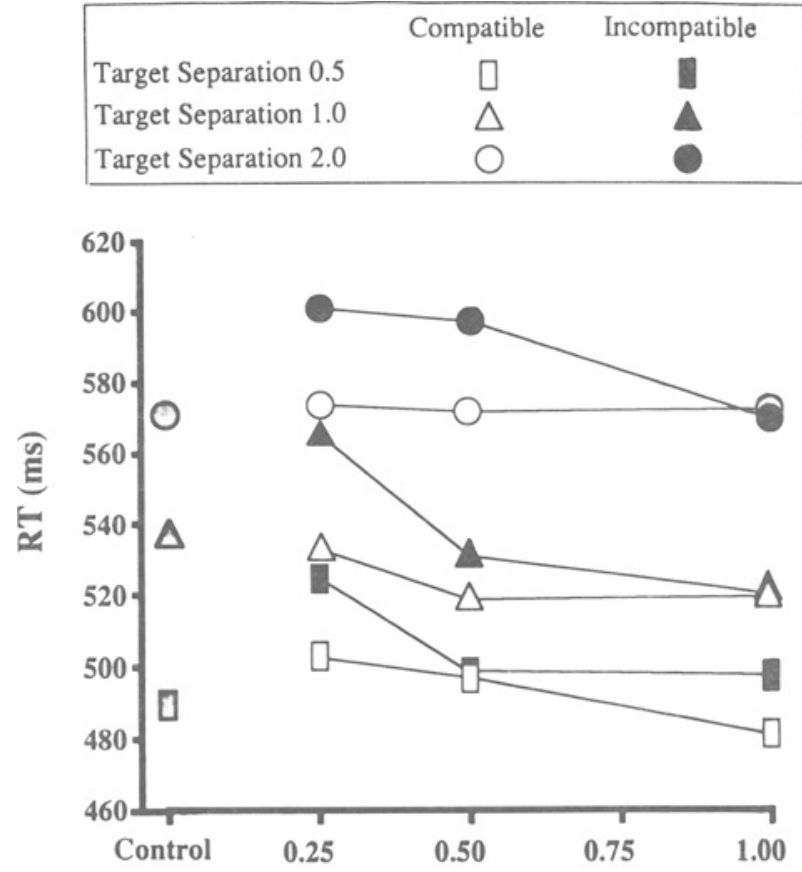

Noise Distance (deg)

Figure 2. Mean correct same judgment reaction times as a function of target separation and noise distance for noise-compatible and noise-incompatible trials. The no-noise control trials are plotted to the left in the figure.

whereas in the noise-incompatible condition, both target separation and noise distance had significant effects $[F(2,22)=40.43$, and $F(3,33)=11.92, p<.0001$, respectively].

At each of the three target distances, a compatible noise letter had little or no effect irrespective of its distance from fixation and the target letters. In no instance did a compatible noise letter differ significantly from the corresponding no-noise control condition $(p>.10$ by planned comparisons). By contrast, an incompatible noise letter increased RT, relative to the control and compatible condition, with the amount of increase dependent on target separation and noise distance. For all target separations, incompatible noise at $0.25^{\circ}$ from the fixation point increased RT significantly relative to the control and compatible conditions ( $p<.05$ by planned comparison). In general, the farther apart the two target letters, the greater the distance at which incompatible noise letter affected RT. When target letters were separated by only $0.5^{\circ}$ of angle, an incompatible noise letter had an effect at only the closest location. But when the targets were separated by 2.0 , incompatible noise significantly increased RT at both the $0.25^{\circ}$ and $0.5^{\circ}$ distances $(p<.05$ by planned comparison). There is also a suggestion in the data that at a target separation of $1.0^{\circ}$ the noise effect at the $0.5^{\circ}$ distance is greater for incompatible than for compatible noise but the incompatible noise value is not significantly different from the no-noise control.
Different judgments. The analysis of variance of the RTs for different trials showed results similar to those obtained with same trials. Both target separation and noise distance had significant effects $[F(2,22)=35.16$, $p<.0001$, and $F(3,33)=4.67, p<.01$, respectively], but the interaction was not significant. In Figure 3, mean RT is shown as a function of noise distance for each of the three target separations.

Planned pairwise comparisons were carried out within each of the target separations. When targets were separated by $0.5^{\circ}$, there were no significant differences among the noise distances. ${ }^{1}$ However, when targets were separated by $1.0^{\circ}$ and $2.0^{\circ}$, RTs were significantly higher when the noise distance was $0.25^{\circ}$ than when it was $0.5^{\circ}$. The RTs at $0.5^{\circ}$ did not differ significantly from the control and $1.0^{\circ}$ distance.

Errors. Overall, errors averaged $7.89 \%$ on same trials and $4.16 \%$ on different trials. A positive correlation existed between latency and errors for both same and different trials ( $r=.86$ and .43 , respectively). Thus, a speed-accuracy tradeoff did not occur.

\section{Discussion}

To summarize the results, let us consider the geometry of the stimuli in the visual field (See Figure 1). In the closest target separation, the targets are each $0.25^{\circ}$ to the left and right (or above and below) the fixation point. When the noise letter is at the $0.25^{\circ}$ distance, all three stimuli can be circumscribed by a circle $0.5^{\circ}$ in diameter. The results show that with this configuration, selective attention did not inhibit the processing of the incompati-

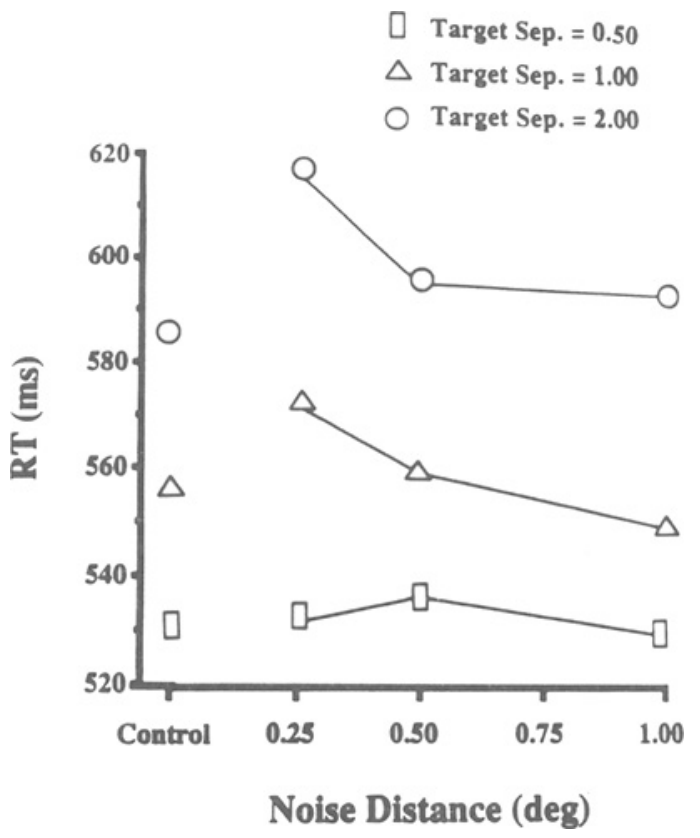

Figure 3. Mean correct different judgment reaction times as a function of target separation and noise distance. The no-noise control trials are plotted to the left in the figure. Note that the noise was always response incompatible on different trials. 
ble noise letter at least to the point of incipient response activation. Even when the targets were moved to locations $0.5^{\circ}$ and $1.0^{\circ}$ on either side of fixation, an incompatible noise letter located at only $0.25^{\circ}$ from fixation continued to produce essentially the same amount of response competition.

This result is inconsistent with the gradient model (LaBerge \& Brown, 1986, 1989) that would posit two nodes of attentional concentration corresponding to the loci of the two target letters. Such a nonuniform distribution of attention should have reduced the processing of the central noise letter.

A circular attentional field with uniform processing within the circle would accommodate the results with the closest noise spacing $\left(0.25^{\circ}\right)$ but not the data from the $0.5^{\circ}$ and $1.0^{\circ}$ spacing. When the targets were separated by $1.0^{\circ}\left(0.5^{\circ}\right.$ left and right or above and below fixation $)$, noise at $0.5^{\circ}$ from fixation would be encompassed by the circle as well as the $0.25^{\circ}$ noise. But with this target separation, only the $0.25^{\circ}$ noise had a significant effect. There is a suggestion that the $0.5^{\circ}$ noise had increased $\mathrm{RT}$, but it is quite clear that the $1.0^{\circ}$ noise was successfully excluded from response interference. When the targets were $2.0^{\circ}$ apart, the attentional field had expanded to include noise at $0.5^{\circ}$ but $1.0^{\circ}$ noise, which would fall within a circular attentional field, had no significant effect. Rather than being a circle, the attended area appears to be elliptical in shape, with the locations of the targets defining the principal axis and the minor axis increasing with increases in the principal axis.

\section{EXPERIMENT 2}

Reaction time for form identification increases as the forms are presented at increasing retinal eccentricities (see, e.g., C. W. Eriksen \& Schultz, 1977, and Haber \& Hershenson, 1974). We found in Experiment 1 that RTs for both same and different trials systematically increased as the targets were spaced farther apart (retinal eccentricities of $0.25^{\circ}, 0.5^{\circ}$, and $1.0^{\circ}$ ). In addition to retinal eccentricity, part of the increase could have been due to less efficient processing as the attentional field was enlarged to encompass the target letters. Whether this is the case cannot be determined, owing to the confounding with retinal locus. But there is another way that retinal eccentricity might have affected the results and their interpretation in Experiment 1. Relative differences in retinal eccentricity between the target letters and the noise letter might have resulted in the noise letter's being processed more slowly than the targets in certain conditions of the experiment and more quickly in other conditions. Thus the lack of effect for an incompatible noise letter at $1.0^{\circ}$ eccentricity when the targets were separated by $0.5^{\circ}$ could have been due to the targets' being further along in processing than the more eccentric noise letter. The result would be that the same-different decision would be determined before sufficient information was available from the noise letter to affect the decision. A somewhat similar effect could have occurred when the targets were separated by $2.0^{\circ}$ and the noise letter was $0.25^{\circ}$ from fixation. Here the noise letter would be processed faster than the target letters.

It is to be noted, however, that the interaction between target separation and the distance of an incompatible noise letter was also present in the conditions in Experiment 1 in which retinal eccentricity was controlled. The incompatible noise letter had no detected effect when the targets were separated by $2.0^{\circ}$ of angle and the noise was at the $1.0^{\circ}$ distance. In this condition, all three stimuli were equally distant from fixation $\left(1.0^{\circ}\right)$. Similarly, when the targets were separated by $1.0^{\circ}$ and the noise was at the $0.5^{\circ}$ distance, all were equally distant from fixation but the effect of an incompatible noise was considerably reduced. Thus the elliptical shape of the attentional field that we found appears to be independent of confounding with retinal eccentricity. Nonetheless, we decided to assess what effect, if any, differences in relative eccentricity might have played in the results from the other conditions of the experiment.

Experiment 1 was replicated but with the following modifications. Only two target separations were used, $0.5^{\circ}$ and $2.0^{\circ}$, along with two noise distances, $0.25^{\circ}$ and $1.0^{\circ}$. In addition to simultaneous presentation of the targets and the noise as in Experiment 1, on one third of the trials the noise letter appeared 25 or $50 \mathrm{msec}$ before the target letters and on another third of the trials the appearance of the noise letter was delayed 25 or $50 \mathrm{msec}$. If the lack of response competition for the $1.0^{\circ}$ noise letter that was found with the $0.5^{\circ}$ target separation in Experiment 1 was due to delayed processing of the noise letter, presentation of the noise letter "early" should result in response competition in this condition. Similarly, if the pronounced competition from the incompatible noise letter at $0.25^{\circ}$ eccentricity when the targets were separated by $2.0^{\circ}$ was due to the early processing of the noise letter, response competition should be eliminated or reduced by delaying the appearance of the noise letter.

\section{Method}

Subjects. Seven women and 2 men, undergraduates at the University of Illinois, Urbana-Champaign, served as paid volunteers. All were right-handed and had normal or corrected-to-normal vision.

Apparatus, Stimuli, and Procedure. The equipment and stimuli were the same as were used in Experiment 1. Here, however, only the two target separations, $0.5^{\circ}$ and $2.0^{\circ}$, and the two noise distances, $0.25^{\circ}$ and $1.0^{\circ}$, were used. In addition to the simultaneous condition (which was identical to the conditions of Experiment 1), on one third of the trials the noise letter was presented either 25 or $50 \mathrm{msec}$ before the target letters (before condition) and on another third of the trials the noise letter was delayed 25 or $50 \mathrm{msec}$ (after condition). In all three conditions, the target letters were presented for a total of $100 \mathrm{msec}$. RT was recorded from the onset of the target letters.

Trials were blocked by target separation, and the remaining variables were randomly arranged within blocks. Each block contained 168 trials, and two blocks for each of the two target separations were run in each experimental session. Each subject served in four sessions. The first session was considered practice, and the data from this session were not included in the data analysis. 


\section{Results and Discussion}

An analysis of the data from the same trials was performed in a five-way ANOVA (target separation, noise distance, noise compatibility, noise-target asynchrony [SOA], and subjects). The main effects for target separation $[F(1,8)=50.52, p<.0005]$, noise compatibility $[F(1,8)=20.60, p<.005]$, and noise-target asynchrony $[F(2,16)=16.28, p<.0005]$ were significant, but the effect for noise distance only approached significance $[F(1,8)=4.18, p<.08]{ }^{2}$ In addition, the interactions of noise distance with compatibility $[F(1,8)=$ $19.64, p<.005$ ] and compatibility with asynchrony $[F(2,16)=4.81, p<.025]$ were also significant.

The results of this analysis were consistent with those of Experiment 1. The small target separation resulted in faster RTs than did the large separation (454 vs. $515 \mathrm{msec}$ ), and compatible noise resulted in faster RTs than did incompatible noise ( 484 vs. $500 \mathrm{msec}$ ). Though not quite significant (see Note 2), noise distance again gave faster RTs when the distance was $1.0^{\circ}$ (496 msec) than when the distance was only $0.25^{\circ}(488 \mathrm{msec})$. The variable that was new in this experiment, noise-target asynchrony, produced faster RTs when the noise preceded the targets $(483 \mathrm{msec})$ than when the noise appeared simultaneously with the targets $(497 \mathrm{msec})$ or after them (498 msec).

In Figure 4, mean RT on the same trials for each of the two target separations is shown as a function of noise compatibility and noise distance when the noise appeared
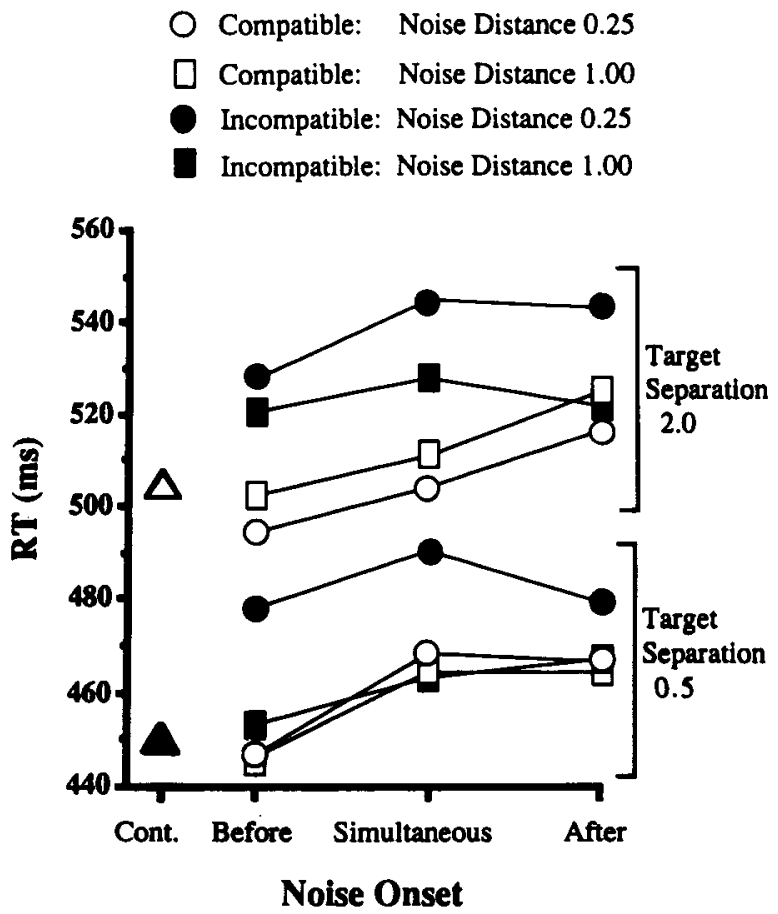

Figure 4. Mean correct same judgment reaction times as a function of noise compatibility and whether the noise onset was before, simultaneous with, or after the onset of the targets. The functions are shown for targets separated by $0.5^{\circ}$ and $2.0^{\circ}$ of visual angle. before, after, or simultaneously with the targets. [The -25 - and -50 -msec SOAs did not differ significantly $(p>.20)$ nor did the 25- and 50-msec SOAs $(p>.30)$. To simplify exposition, the -25 - and -50 -msec SOAs have been averaged together as before values and the 25 and 50-msec SOAs as after values.] The effect of target separation is clearly apparent with the bottom four curves in the figure corresponding to the $0.5^{\circ}$ separation. If we examine first this set of curves, we see that the curve for incompatible noise at the $1.0^{\circ}$ distance is indistinguishable from the curves for the compatible noise at the $0.25^{\circ}$ and $1.0^{\circ}$ distances. In other words, there was no detectable response competition when the targets were at $0.5^{\circ}$ separation $\left(0.25^{\circ}\right.$ on either side of the fixation point) and the incompatible noise letter was $1.0^{\circ}$ from the fixation point on the orthogonal meridian. However, there was a pronounced response-competition effect at this target separation if the incompatible noise letter was at the $0.25^{\circ}$ distance. Most importantly, this response-competition effect was but little affected by whether the noise letter was presented before or simultaneously with the target letters.

The four upper curves in the figure show somewhat comparable effects for the $2.0^{\circ}$ target separation. Since compatible noise letters were not expected to show response competition, it is not surprising that there is little difference between compatible noise letters presented at the $0.25^{\circ}$ and $1.0^{\circ}$ distances. But again there was a marked competition effect for the incompatible noise letter at the $0.25^{\circ}$ distance, and in this case, there was also a suggestion of competition at the $1.0^{\circ}$ distance. The competition effect from the $1.0^{\circ}$ distant noise letter was not detected in Experiment 1, but it is to be noted that it is significantly less than the competition produced by the $0.25^{\circ}$ noise letter ( $p<.05$ by planned comparison) when the noise letters were presented simultaneously with and after the targets. Furthermore, the competition does not differ significantly from the comparable RTs obtained with the compatible noise letter $(p<.10)$.

It is clear from the results above that the noise distance effects obtained in Experiment 1 and in the present experiment cannot be attributed to slower processing (in the case of the $1.0^{\circ}$ distance) or more rapid processing (in the case of the $0.25^{\circ}$ distance) due to differences in retinal eccentricity between the incompatible noise letter and the targets. With the $0.5^{\circ}$ target separation, an incompatible noise letter at the $1.0^{\circ}$ distance did not produce response competition even if it was given a $25-50 \mathrm{msec}$ head start. Also, this head start did not materially increase the response competition of the noise letter at the $0.25^{\circ}$ distance over the effect obtained when noise and targets appeared simultaneously.

With the $2.0^{\circ}$ target separation, there is a suggestion that the head start may have increased the potency of the noise letter at the $1.0^{\circ}$ distance, but the effect is not significantly greater than the effect when targets and noise occur simultaneously. Equally important is the finding that the response competition produced by the incompatible noise at the $.25^{\circ}$ distance is not attributable to its processing advantage over the targets due to its more favora- 
ble retinal locus. Delaying the onset of the noise letter by 25 or $50 \mathrm{msec}$ did not diminish its response-competition effects.

There was a significant main effect for noise onset asynchrony in the ANOVA, and the curves in Figure 4 show that this is attributable to overall faster RTs when the noise letter onset preceded the targets. The effect is most clear in the data for the compatible noise letter, where responsecompetition effects are absent. A possible explanation for this RT facilitation is an alerting or first signal effect that has been a finding in comparable experimental arrangements (see C. W. Eriksen \& Murphy, 1987). However, since the effect is mainly obtained with the compatible noise, the effect is most comparable to the results of Flowers and Wilcox (1982). Like other investigators, Flowers and Wilcox found little or no effect of compatible noise when targets and noise were presented simultaneously, but when the compatible noise onset preceded the target by SOAs of 50 or $67 \mathrm{msec}$, compatible noise facilitated choice RTs.

As we pointed out above, response-competition effects, although present, are less robust and reliable for different responses than for same responses. The RTs obtained on the different trials were analyzed in a four-way ANOVA (target separation, noise distance, noise asynchrony, and subjects). The main effects for target separation $[F(1,8)=48.3, p<.001]$ and noise distance $[F(1,8)=8.58, p<.025]$ were significant and reflected the same pattern of differences that was obtained with the same trials. The effect of noise asynchrony did not approach significance $[F(2,16)=0.42]$, nor did any of the interactions.

Overall, errors averaged $10.2 \%$ on same trials and $8.4 \%$ on different trials. A positive correlation existed between latency and errors for same and different trials $(r=$ .61 and .57 , respectively). Thus, again, a speed-accuracy tradeoff did not occur.

\section{GENERAL DISCUSSION}

\section{Summary of Findings}

Previous experiments that we have cited above have amply demonstrated that response-competitive stimuli within about a degree of angle or less of attended targets are processed at least to the point of identification and incipient response activation. But these experiments have provided us with only limited information about the attended area. The use of two attended targets in the same-different task has enabled us in the present experiments to manipulate the extent of the attended area and to map its two-dimensional characteristics.

The major finding of Experiment 1 and its replication in Experiment 2 is that the effect of an irrelevant stimulus depends on its location in the visual field relative to the area requiring attention. A response-incompatible stimulus positioned at a constant location from the fixation point may or may not increase $\mathrm{RT}$, depending on how attention is distributed to accomplish the assigned task.
In keeping with the spotlight metaphor, the results obtained with single-target stimuli (e.g., Andersen, 1990; C. W. Eriksen \& Hoffman, 1974; Flowers \& Wilcox, 1982; Miller, 1991) have suggested that the attentional field is essentially circular, since the interference effect of response-incompatible stimuli has been found to be a function of their distance from the target irrespective of the direction. The present results show quite clearly that circularity is not an inherent characteristic of the attentional field. Instead, the indications are that the shape is flexible, determined by the spatial arrangement of the attended or target objects. In the present instance, the shape appears to be elliptical, but this shape may be determined by the fact that there were only two targets to be attended. It may well be that the attentional field can assume different configurations, depending on where the relevant stimuli are positioned and corresponding with task demands.

Furthermore, the present findings on the shape of the attentional field are limited, since we have assessed the field only for foveal stimuli. The ratio of principal and minor axes on the ellipse may change for parafoveal stimuli, and the ellipse itself may occur only when there are two separated targets. Also, the attentional field would be expected to be limited as a function of the demands of the task and the discrimination difficulty. With difficult discriminations, the size of the field appears to narrow (LaBerge \& Brown, 1989). If the discriminations in the present experiments had been more difficult, it is possible that attention would have been oriented serially to each of the targets, and, consequently, each target would have had a much smaller and probably circular field surrounding it.

\section{Serial Versus Parallel Processing of Targets}

So far we have assumed that both targets are processed simultaneously in a common attentional field, but the possibility of serial processing needs to be considered. Attention could select one target first, and, after processing is initiated, shift to the other target. However, there are several aspects of the data that argue against this. A serial explanation has difficulty in accounting for the pattern of noise interference. One could assume that the attentional focus has a minimal spatial extent, and that, at the closest target separation, the targets and noise are processed in this minimal focus. This would account for the response competition obtained when the incompatible noise is at $0.25^{\circ}$ and the targets are separated by $0.5^{\circ}$. But when the targets are separated by $2.0^{\circ}$, competition is found for noise at $0.5^{\circ}$ as well. In this instance, the noise is separated from each target by a distance of $1.12^{\circ}$ (hypotenuse of a right triangle). If it is argued that the resolution of the separate attentional foci is not sufficient to exclude the $0.5^{\circ}$ noise letter, then why is the $0.5^{\circ}$ noise letter excluded when the targets are separated by only $1.0^{\circ}$ ?

As a further example, assume that the attentional focus is circular, with a minimum diameter of $1.0^{\circ}$. With the $1.0^{\circ}$ separation of targets, a single focus would include 
both targets and the noise letter at the $0.25^{\circ}$ distance. Thus, response competition would occur. But at the $2.0^{\circ}$ target separation and with serial attending of the targets, centering the focus on each target serially would exclude not only the noise letter at the $0.5^{\circ}$ distance but also the noise letter at $0.25^{\circ}$. And this is contrary to our findings.

To salvage such a model, one could posit that the noise letters are picked up during the attentional shift from one target to the other. To make this plausible would also require the assumption that the analog shift of attention follows a curved path with the degree of curvature increasing with the distance between successive fixations. The latter assumption would be necessary to account for why noise at the $0.5^{\circ}$ distance is picked up when the targets are $2.0^{\circ}$ apart but not when they are separated by only $1.0^{\circ}$.

Shulman, Remington, and McLean (1979) have advanced an attentional model in which attention shifts in such an analog manner, traversing the visual field between targets and processing all intervening stimuli that are encountered en route. However, a reanalysis of their experiments and data (C. W. Eriksen \& Murphy, 1987) fails to support such a conclusion. Furthermore, subsequent research has strongly indicated that attention either shifts or indexes locations in the visual field in a discrete manner with the time required for shifts from one location to another to be independent of the distance between the locations (C. W. Eriksen \& Webb, 1989; Kwak, Dagenbach, \& Egeth, 1991; Murphy \& C. W. Eriksen, 1987; Sagi \& Julesz, 1985).

\section{An Explanation in Terms of Sudden Onsets}

There is another possible explanation of our results that must be considered, one that is consistent with objectbased theories of attention. In this view, the sudden onset of the two target letters and the noise letter results in attention's being randomly directed to one of the three stimuli (Jonides \& Yantis, 1988; Yantis \& Jonides, 1984). On a same trial, attention has a one-third probability of first selecting the incompatible noise letter. When attention is next directed to one of the target stimuli, a "different" response will receive priming that will tend to slow the "same" response that is correctly executed after the two target letters have been processed (see van der Heijden, 1992, chap. 6, for a more detailed exposition of this position). From this viewpoint, attention does not have any spatial representation. Instead, it selects objects in the visual field, and with sudden onsets, which stimulus is initially selected is essentially random. If an incompatible noise letter is selected first, response competition occurs. With three sudden onset stimuli in the field, response competition would be expected to occur on approximately a third of the trials. Since our data are averaged over a number of trials, we cannot determine whether response competition is present in varying degrees on each trial or only on a third of the trials as this model predicts.

However, a detailed consideration of the data from Experiment 1 strongly refutes this interpretation. With the $2.0^{\circ}$ target separation and noise at $1.0^{\circ}$, all three stimuli onset at the same time and all were $1.0^{\circ}$ from fixation. According to the object model of attention, an incompatible noise letter should have been selected on a third of the trials under these conditions and significant response competition should have been obtained. But the results show that no detectable competition occurred under these conditions. Similarly, when targets were separated by $1.0^{\circ}$ and noise was at $0.5^{\circ}$ (all equally distant from fixation), no significant competition effect was obtained, contrary to the prediction of an object-based model. In contrast, with $0.5^{\circ}$ target separation and noise at $0.25^{\circ}$, a considerable competition effect was obtained.

The data from Experiment 2 are also quite inconsistent with a "sudden onset object-based" view of attention. Here, in the before condition, the noise letter had an onset of 25 or $50 \mathrm{msec}$ before the onsets of the two target letters. Turning the noise letter on before the targets would certainly seem to bias attentional selection of the noise letter first and increase the competition effect from an incompatible noise letter. Yet our results show that the early onset of an incompatible noise letter did not significantly or materially increase the competition effect over the condition where all three stimuli onset simultaneously.

\section{The Attention Field as an Inhibition Free Area}

Although it is quite clear that attention has measurable spatial effects in the visual field, this does not necessarily require that attentional selection is based on location rather than on objects. Attention is more than selection. Van der Heijden (1992) has recently reminded us of the role of intention and expectancy, and it has long been recognized that attention can have inhibitory effects as well as possible facilitating effects on stimulation (see, e.g., Treisman, 1969). We suggest that the attentional field effects that we have found in the present experiments may represent inhibition or attenuation of irrelevant stimuli rather than a positive selection mechanism. In other words, with our response-competition paradigm, we have been measuring the inner limits of an inhibitory field around the attended or selected stimuli, rather than the outer limits of an activated field surrounding the attended stimulus location.

There is a growing body of experimental evidence showing the role of inhibition in stimulus processing and stimulus selection (see, e.g., Allport, Tipper, \& Chmiel, 1985; Dalrymple-Alford \& Budayr, 1966; Lowe, 1979, 1985; Neill, 1977; Neill \& Westberry, 1987; Tipper, 1985; Tipper, MacQueen, \& Brehaut, 1988).

Neill (1991) has presented an excellent summary of the research in this area and traced out some of its theoretical implications. Most importantly, in the responsecompetition paradigm, distracting flankers have been found to produce negative priming (Neill, 1992, personal communication). If a stimulus that was a competitive flanker on trial $n$ is now the target on trial $n+1$, RT is increased over conditions in which the target stimulus on trial $n+1$ was not a distractor on the preceding trial. These results suggest strongly that inhibitory processes are oper- 
ating on noise stimuli such as those employed in the present experiments.

The response-competition effects demonstrated in the present experiments and in a number of other investigations summarized above would almost require the inhibition of irrelevant stimulation in order for fast, efficient responses to the relevant or attended stimuli to be achieved. In accord with late-selection views of attention, a large number of stimuli can be processed simultaneously to the level of identification. But selection alone is not sufficient to insure rapid error-free responding, particularly when some of the identified stimuli lead to the incipient activation of competing or interfering responses or behaviors. From a late-selection position, we would expect that all the noise stimuli were identified in the present experiments irrespectively of their distance from the target stimuli, especially since all stimulation was foveal. But only the noise stimuli that were within a given distance of the targets were found to have measurable response effects. We believe that these distance effects are measures of the effectiveness of inhibition of inputs and that this inhibition has a central locus (Tipper et al., 1988).

As contrasted with a spotlight, Navon (1990) has proposed an aperture metaphor for visual attention. While a spotlight metaphor implies signal enhancement, an aperture is consistent with inhibition or attenuation of nonattended stimuli. We would modify the aperture concept by providing not only for variable size and shape to the aperture but also for varying opacity for the screen or shutter. The results of the present experiments would require that the aperture assume various shapes and sizes, and consideration of the broader manifestations of attention would require that the inhibitory screen vary in intensity of inhibition. Attention is not an "all or none"' mechanism. Common observation of our own behavior confirms that there are levels or degrees of attention. The degree of inhibition as well as aperture size would be expected to vary with the intensity of attention. In the experimental paradigms that we have used, attention and its intensity have been measured solely in terms of aperture size and shape, but the experimental instructions to the subjects can be presumed to have induced inhibitory processes at several levels of processing. The instructions have specified what motor responses are to be used, the nature of the presented stimuli, and the mental operations to be performed. These instructions may have placed these relevant responses and mental operations in a heightened state of readiness, but also a level of inhibition has been established for other possible responses or mental operations. The result is a highly selective set of behaviors from the subjects.

We suspect that the level of inhibition that the subjects have exerted on the noise stimuli in the present tasks has been tailored to the demands of the primary task. Even though we found that a response-competitive stimulus at a certain spatial distance or separation had been successfully inhibited, the degree of inhibition is probably not much more than was necessary for successful performance. In the dichotic listening task, the presentation of the subject's name or an unusual stimulus in the nonattended ear generally results in disruption of performance (Moray, 1959). In the present tasks, we would expect similar results. If the subject's name or a "dirty" word had been presented at a noise location where incompatible stimuli had had no observable effect, the inhibition would probably have been insufficient to prevent performance disruption.

\section{REFERENCES}

Allfort, D. A., Tipper, S. P., \& Chmiel, N. (1985). Perceptual integration and post-categorical filtering. In M. I. Posner \& O. S. M Marin (Eds.), Attention and performance XI (pp. 107-132). Hillsdale, NJ: Erlbaum.

ANDERSEN, G. J. (1990). Focused attention in three-dimensional space. Perception \& Psychophysics, 47, 112-120.

Coles, M., Gratton, G., Bashore, T. R., Eriksen, C. W., DonCHIN, E. (1985). A psychophysiological investigation of the continuous flow model of human information processing. Joumal of Experimental Psychology: Human Perception \& Performance, 11, 529-533.

DALRYMPLE-Alford, E. C., \& BUdAyr, B. (1966). Examination of some aspects of the Stroop colour-word test. Perceptual \& Motor Skills, 23, 1211-1214.

Downing, C. J. (1988). Expectancy and visual-spatial attention: Effects on perceptual quality. Joumal of Experimental Psychology: Human Perception \& Performance, 14, 188-202.

Downing, C. J., \& Pinker, S. (1985). The spatial structure of visual attention. In M. I. Posner \& O. S. M. Marin (Eds.), Attention and performance $X I$ (pp. 171-187). Hillsdale, NJ: Erlbaum.

Driver, J., \& Bay LIS, G. C. (1989). Movement and visual attention: The spotlight metaphor breaks down. Joumal of Experimental Psychology: Human Perception \& Performance, 15, 448-456.

DunCan, J. (1980). The locus of interference in the perception of simultaneous stimuli. Psychological Review, 87, 272-300.

ERIKSEN, B. A., \& ERIKSEN, C. W. (1974). Effects of noise letters upon the identification of a target letter in a nonsearch task. Perception \& Psychophysics, 16, 143-149.

Eriksen, C. W., Coles, M. G. H., Morris, L. R., \& O'Hara, W. P. (1985). An electromyographic examination of response competition. Bulletin of the Psychonomic Society, 23, 165-168.

Eriksen, C. W., \& Hoffman, J. E. (1973). The extent of processing of noise elements during selective encoding from visual displays. Perception \& Psychophysics, 14, 155-160.

Eriksen, C. W., \& Hoffman, J. E. (1974). Selective attention: Noise suppression or signal enhancement? Bulletin of the Psychonomic Society, 4, 587-589.

ERIKSEN, C. W., \& MurPhy, T. D. (1987). Movement of the attentional focus across the visual field: A critical look at the evidence. Perception \& Psychophysics, 42, 299-305.

ERIKSEN, C. W., \& O'HARA, W. P. (1982). Are nominal same-different matches slower due to differences in level of processing or to response competition? Perception \& Psychophysics, 32, 335-344.

Eriksen, C. W., O'Hara, W. P., \& ERIKSEN, B. [A.] (1982). Response competition effects in same-different judgments. Perception \& Psychophysics, 32, 261-270.

ERIKSEN, C. W., \& SCHultz, D. W. (1977). Retinal locus and acuity in visual information processing. Bulletin of the Psychonomic Society, 9, 81-84

ERIKSEN, C. W., \& St. JAmES, J. D. (1986). Visual attention within and around the field of focal attention: A zoom lens model. Perception \& Psychophysics, 40, 225-240.

Eriksen, C. W., \& WeBs, J. M. (1989). Shifting of attentional focus within and about a visual display. Perception \& Psychophysics, 45, 175-183. 
ERIKSEN, C. W., \& YeH, Y. (1985). Allocation of attention in the visual field. Joumal of Experimental Psychology: Human Perception \& Performance, 11, 583-597.

Estes, W. K. (1978). Perceptual processing in letter recognition and reading. In E. C. Carterette \& M. P. Friedman (Eds.), Handbook of perception (Vol. 9, pp. 163-255). New York: Academic Press.

FARELL, B. (1985). "Same-different" judgments: A review of current controversies in perceptual comparisons. Psychological Bulletin, 98, 419-456.

Flowers, J. H., \& WILcox, N. (1982). The effect of flanking context on visual classification: The joint contribution of interactions at different processing levels. Perception \& Psychophysics, 32, 581-591.

GARNER, W. R. (1988). Facilitation and interference with a separable redundant dimension in stimulus comparison. Perception \& Psychophysics, 44, 321-330.

HABer, R. N., HeRshenson, M. (1974). The psychology of visual perception. London: Holt, Rinehart \& Winston.

Hughes, H. C., \& ZimBA, L. D. (1985). Spatial maps of directed visual attention. Journal of Experimental Psychology: Human Perception \& Performance, 11, 409-430.

Hughes, H. C., \& ZimbA, L. D. (1987). Natural boundaries for the spread of directed visual attention. Neuropsychologica, 2, 5-18.

JoNIDES J., \& YANTIS, S. (1988). Uniqueness of abrupt visual onset in capturing attention. Perception \& Psychophysics, 43, 346-354.

Kahneman, D., \& Henik, A. (1981). Perceptual organization and attention. In M. Kubovy \& J. R. Pomerantz (Eds.), Perceptual organization (pp. 181-211). Hillsdale, NJ: Erlbaum.

Keren, G., O'Hara, W. P., \& Skelton, J. (1977). Levels of noise processing and attention control. Journal of Experimental Psychology: Human Perception \& Performance, 3, 653-664.

Krueger, L. E. (1978). A theory of perceptual matching. Psychological Review, 85, 278-304.

Kwak, H.-W., Dagenbach, D., \& Egeth, H. (1991). Further evidence for a time-independent shift of the focus of attention. Perception \& Psychophysics, 49, 473-480.

LABERGE, D. (1983). Spatial extent of attention to letters in words. Journal of Experimental Psychology: Human Perception \& Performance, 9, 371-379.

LABERGE, D., \& BRowN, V. (1986). Variations in size of the visual field in which targets are presented: An attentional range effect. Perception \& Psychophysics, 40, 188-200.

LABERGE, D., \& Brown, V. (1989). Theory of attentional operation in shape identification. Psychological Review, 96, 101-124.

LowE, D. G. (1979). Strategies, context, and the mechanism of response inhibition. Memory \& Cognition, 7, 382-389.

LowE, D. G. (1985). Further investigations of inhibitory mechanisms in attention. Memory \& Cognition, 13, 74-80.

MILLER, J. (1991). The flanker compatibility effect as a function of visual angle, attentional focus, visual transients, and perceptual load: A search for boundary conditions. Perception \& Psychophysics, 49, 270-288.

MoRaY, N. (1959). Attention in dichotic listening: Affective cues and the influence of instructions. Quarterly Journal of Experimental Psychology, 11, 56-60.

MURPHY, T. D., E ERIKSEN, C. W. (1987). Temporal changes in the distribution of attention in the visual field in response to precues. Perception \& Psychophysics, 42, 576-586.

Navon, D. (1990). Does attention serve to integrate features? Psychological Review, 97, 453-459.

NEILL, W. T. (1977). Inhibitory and facilitatory processes in selective attention. Journal of Experimental Psychology: Human Perception \& Performance, 3, 444-450.

NeILL, W. T. (1991). Consciousness and the inhibitory control of attention. Invited address to Division 3 of the American Psychological Association, San Francisco.

NeILL, W. T., WestrerRY, R. L. (1987). Selective attention and the suppression of cognitive noise. Journal of Experimental Psychology: Leaming, Memory, \& Cognition, 13, 327-334.
O'HaRA, W. P. (1980). Evidence in support of word unitization. Perception \& Psychophysics, 27, 390-402.

PosNer, M. I., SNyder, C. R. R., \& DAVIDSON, B. J. (1980). Attention and the detection of signals. Journal of Experimental Psychology, 2, 160-174.

Prinzmetal, W. (1981). Principles of feature integration in visual per ception. Perception \& Psychophysics, 30, 330-340.

SAGI, D., \& JULESZ, B. (1985). Fast noninitial shifts of attention. Spatial Vision, 1, 141-149.

Shulman, G. L., Remington, R. W., \& Mclean, J. P. (1979). Moving attention through visual space. Journal of Experimental Psychology: Human Perception \& Performance, 5, 522-526.

ST. JAMES, J. D., \& ERIKSEN, C. W. (1991). Response competition produces a "fast same effect" in same-different judgements. In J. Pomerantz \& G. Lockhead, (Eds.), The perception of structure (pp. 157-168). Washington, DC: American Psychological Association.

TIPPER, S. P. (1985). The negative priming effect: Inhibitory priming by ignored objects. Quarterly Journal of Experimental Psychology, 37A, 571-590.

Tipper, S. P., MacQueen, G. M., \& Brehaut, J. C. (1988). Negative priming between response modalities: Evidence for the central locus of inhibition in selective attention. Perception \& Psychophysics, $43,45-52$.

Treisman, A. M. (1969). Strategies and models of selective attention. Psychological Review, 76, 282-299.

Treisman, A., \& Gelade, G. (1980). A feature integration theory of attention. Cognitive Psychology, 12, 97-136.

Treisman, A., \& Souther, J. (1985). Search asymmetry: A diagnostic for preattentive processing of separable features. Journal of Experimental Psychology: General, 114, 285-310.

TsaL, Y. (1983). On interpreting the effects of location preknowledge: A critique of Duncan. Perception \& Psychophysics, 34, 297-298.

TSAL, Y., \& LAvIE, N. (1988). Attending to color and shape: The special role of location in selective visual processing. Perception \& Psychophysics, 44, 15-21.

VAN DER HEIJDEN, A. H. C. (1992). Selective attention in vision. London/New York: Routledge.

van der Heiden, A. H. C., Schreuder, R., \& Wolters, G. (1985). Enhancing single-item recognition accuracy by cueing spatial locations in vision. Quarterly Joumal of Experimental Psychology, 37A, 427-434.

van der Heijden, A. H. C., Wolters, G., \& Enkeling, M. (1988). The effects of advance location cueing on latencies in a single-letter recognition task. Psychological Research, 50, 94-102.

Yantis, S., \& Johnston, J. C. (1990). On the locus of visual selection: Evidence from focused attention tasks. Journal of Experimental Psychology: Human Perception \& Performance, 16, 135-149.

YANTIS, S., \& Jonides, J. (1984). Abrupt visual onsets and selective attention: Evidence from visual search. Journal of Experimental Psychology: Human Perception \& Performance, 10, 601-621.

\section{NOTES}

1. The failure to obtain an appreciable and significant effect for incompatible noise at the $0.25^{\circ}$ distance when the targets were separated by $0.5^{\circ}$ is anomalous. In two unpublished experiments from our laboratory, this condition was replicated as part of more extensive investigations, and in both instances significant and appreciable competition effects were obtained for different judgments.

2 . In this analysis, the compatible trials water down noise distance effects since they do not provide response competition. If only the incompatible trials are analyzed, significant noise distance effects are obtained.

(Manuscript received May 8, 1992; revision accepted for publication July $2,1992$. 